\title{
ADDENDUM
}

\section{Unheard voices: outcomes of tertiary care for treatment-refractory psychosis - ADDENDUM}

S. Neil Sarkar, Derek K. Tracy, Maria-Jesus Mateos Fernandez, Natasza Nalesnik, Gurbinder Dhillon, Juliana Onwumere, Anne-Marye Prins, Karen Schepman, Tracy Collier, Thomas P. White, Anita Patel, Fiona Gaughran, Sukhwinder S. Shergill

BJPsych Bulletin (2019) 43, 194, doi:10.1192/bjb.2019.40

(c) The Authors 2019. This is an Open Access article, distributed under the terms of the Creative Commons Attribution licence (http://creativecommons.org/ licenses/by/4.0/), which permits unrestricted re-use, distribution, and reproduction in any medium, provided the original work is properly cited.

https://doi.org/10.1192/pb.bp.112.042598, Published online by the Royal College of Psychiatrists, 2nd January 2018

There was an oversight regarding the acknowledgement of funding from the European Research Council, which was a contractual obligation for the funding. Professor Sukhwinder S. Shergill was funded by an ERC Consolidator Award.

\section{Reference}

Sarkar SN, Tracy DK, Fernandez M-JM, Nalesnik N, Dhillon G, Onwumere J, Prins $A-M$, et al. Unheard voices: outcomes of tertiary care for treatment-refractory psychosis. The Psychiatr Bull 2014; 38: 71-74. 